\title{
Diabetes Mellitus Is Associated with Hepatocellular Carcinoma: A Retrospective Study in Southwest China
}

\author{
Yi-Shu Tang*, Lang Wu and Fang Cui \\ Department of Laboratory Medicine, The First Affiliated Hospital of Chongqing Medical University, Chongqing, People's Republic of China
}

\begin{abstract}
Background and aims: A lot of case-control patient studies have investigated the association between diabetes mellitus (DM) and hepatocellular carcinoma (HCC). Despite some controversial reports, it has been suggested that DM is associated with HCC. Therefore, it is necessary to delineate the involvement of DM, together with other related risk factors, in HCC with large sample size and strict analysis methodology.
\end{abstract}

Methods: We conducted a hospital-based retrospective case-control study in Chongqing. In total, 352 patients with liver diseases were enrolled in the study to evaluate the association of DM and other risk factors with HCC. Among all these patients, 190 patients were diagnosed with benign liver diseases, and 162 patients were diagnosed with HCC. We utilized binary logistic regression and stepwise logistic regression to investigate the associations among DM, hypertension, fatty liver, cirrhosis, gallstone, HBV infection, and HCC.

Results: The stepwise regression model indicated that the prevalence of DM, male gender, cirrhosis, or HBV infection is higher in the HCC patient group compared to the control group.DM co-exists with $\mathrm{HBV}$ infection, male gender, and age in the HCC cases. Binary logistic regression analysis suggested that DM may synergize with $\mathrm{HBV}$ infection in $\mathrm{HCC}$ development. DM is associated with the increased risk of $\mathrm{HCC}$ regardless of the prevalence of male gender, cirrhosis, HBV infection, and age.

Conclusions: The synergistic interaction between DM and HBV in HCC occurrence is significant. Therefore, DM patients with HBV infection represent a very highrisk population and should be considered for HCC close surveillance program.

\section{Introduction}

Hepatocellular carcinoma (HCC) is one of the most common cancers worldwide [1]. Infection with hepatitis viruses are the leading risk factors for HCC. China accounted for over $50 \%$ of HCC cases worldwide, with over $70 \%$ of HCC cases linking to hepatitis B virus (HBV) infection.

Increasing evidences suggested diabetes mellitus (DM) have strong association with the incidence of HCC [2,3]. Although there were some controversial reports [4], DM has been suggested as a risk factor for the development of HCC. However, other risk factors, such as HBV, hypertension, fatty liver, and cirrhosis, are involved in the development of HCC in the presence of DM, which has not been well documented. Only a few studies have followed populations with both chronic HBV infection and metabolic disorders. Most studies used the normal population or cancers as controls, and liver pathology and metabolic disorders were not well matched between cases and controls. Additionally, it has been speculated that DM may synergize with other risk factors, such as age, male, gender for the development of HCC.

In this study, we conducted a hospital-based case-control study to investigate the association between DM and HCC in the presence of other risk factors and strict analysis methodology. We concluded that $\mathrm{DM}$ represents an independent or synergizing risk factor with HBV, age, or male gender for HCC development in Chongqing population.

\section{Methods}

\section{Ethics statement}

We conducted a retrospective case-control study on liver disease based on the liver disease patients in the First Affiliated Hospital of Chongqing Medical University, from May 2015 to September 2016.This study was approved by the Institutional Review Board (IRB) committee of The First Affiliated Hospital of Chongqing Medical University (approval documents attached). Written consent given by the patients was waived by the approving IRB.

\section{Study subjects}

Cases were patients $<70$ years of age with benign liver diseases or HCC that went through surgeries in Chongqing. The case selection criteria include: the patients have full blood testing information; the first time patients (the returning patient cases were removed from the study); and the HCC patients had yet received any cancer treatment at study entry.

Correspondence to: Yi-Shu Tang, Department of Laboratory Medicine, The First Affiliated Hospital of Chongqing Medical University, No. 1 Youyi Road, Yuzhong District, 400016, Chongqing, People's Republic of China, Tel: +86-23-89012513; Fax: +86-23-89012513; E-mail: 916403117@qq.com

Received: June 22, 2017; Accepted: July 12, 2017; Published: July 14, 2017 
In total, 352 participants had complete diagnostic records. Among all these patients, 190 patients were diagnosed with benign liver diseases, and 162 patients were diagnosed with HCC.

\section{Statistical analysis}

The distribution of the study variables was calculated using means with standard deviations for normal continuous variables or using median with quartile range for skewness variables, and frequencies and percent for categorical variables. For continuous variable comparisons, Student's t tests were used when equality of variances was satisfied, otherwise Satterthwaite-tests were conducted. We assessed effect of each "risk" factor for HCC using binary logistic regression. Stepwise logistic regression was performed in this study to find the most parsimonious set of predictors that are most effective in predicting HCC.

\section{Results}

\section{Comparison of risk factors between HCC cases and their controls}

Among all these patients, 352 participants had complete diagnostic records. Among all these patients, patients were diagnosed with benign liver diseases, and 162 patients were diagnosed with HCC. Among all these patients, 190 patients were diagnosed with benign liver diseases, and 162 patients were diagnosed with HCC. Among these HCC patients, there were 142 men $(87.7 \%)$ with a mean age of $57.49 \pm 11.86$ years; 144 patients $(88.9 \%$ ) were positive for HBsAg (Table 1).

\section{Comparison of Blood Risk Factors between the HCC and Controls Groups}

Comparison of blood risk factors between the HCC and controls groups indicates significant differences between these two groups on age, ALT, AST, LDH, GGT, ALP, TBA, CHE, GLU, BU and BC (Table 2). However, there was no significant difference in TG levels between HCC and control groups.

\section{The analysis of factors for hepatocellular carcinoma by binary regression}

Table 3 shows odds ratios by binary logistic regression model. The risk factors that are strongly associated with HCC include: male gender $(\mathrm{OR}=5.6, \mathrm{p}<0.05), \mathrm{HBsAg}(\mathrm{OR}=2.401, \mathrm{p}<0.05), \mathrm{HCV}$ infection $(\mathrm{OR}$ $=6.46, \mathrm{p}<0.0001)$, cirrhosis $(\mathrm{OR}=4.417, \mathrm{p}<0.05), \mathrm{DM} 2(\mathrm{OR}=1.827$, $\mathrm{p}<0.05)$, and portal hypertension $(\mathrm{OR}=5.231, \mathrm{p}<0.05)$. There is no significant correlation between Hypertension and $\mathrm{HCC}(\mathrm{OR}=1.137, \mathrm{p}$ $=0.768)$. We found that risk factors that are negatively correlated with HCC include:

$\mathrm{Tch}(\mathrm{OR}=0.473, \mathrm{p}=0.047)$, and Apoa $1(\mathrm{OR}=0.67, \mathrm{p}=0.019)$.

Table 1. Comparison of Clinical indicators between HCC and Control groups.

\begin{tabular}{|c|c|c|c|c|c|c|}
\hline Variable & \multicolumn{2}{|c|}{ Control (n=190) } & HCC (n=162) & & $\mathbf{X}^{2}$ & P \\
\hline & Frequency & Percent & Frequency & Percent & & \\
\hline Male & 124 & $65.3 \%$ & 142 & $87.7 \%$ & 23.746 & $<0.001$ \\
\hline HBSAg $^{+}$ & 110 & $57.9 \%$ & 144 & $88.9 \%$ & 41.813 & $<0.001$ \\
\hline Anti-HCV & 9 & $4.7 \%$ & 3 & $2.1 \%$ & 2.21 & 0.137 \\
\hline Portal pertension & 154 & $81.1 \%$ & 113 & $70.0 \%$ & 6.095 & 0.014 \\
\hline Diabetes & 26 & $13.7 \%$ & 20 & $12.3 \%$ & 0.138 & 0.028 \\
\hline Hypertension & 24 & $12.6 \%$ & 21 & $13.0 \%$ & 0.009 & 0.926 \\
\hline Fatty liver & 4 & $2.1 \%$ & 1 & $0.6 \%$ & 1.41 & 0.235 \\
\hline Cirrhosis & 178 & $93.7 \%$ & 160 & $98.8 \%$ & 44.813 & $<0.001$ \\
\hline
\end{tabular}

Table 2. Comparison of blood indicators between HCC and Control groups.

\begin{tabular}{|c|c|c|c|}
\hline Variable & $\begin{array}{c}\text { Control (Mean } \pm \\
\text { SD/Median Q1-Q3) }\end{array}$ & $\begin{array}{c}\text { HCC (Mean } \pm \\
\text { SD/MedianQ1-Q3) }\end{array}$ & p \\
\hline Age & $54.12 \pm 12.19$ & $56.2 \pm 11.2$ & 0.12 \\
\hline ALT & $41.845(12.75,44.25)$ & $112.93(35,93)$ & $<0.001$ \\
\hline AST & $59.76(27,61.75)$ & $213.4(57.75,228)$ & $<0.001$ \\
\hline GGT & $25.25(27,118.5)$ & $272.6(79,333.75)$ & $<0.001$ \\
\hline ALP & $128.6(77,142)$ & $249(126.25,292)$ & $<0.001$ \\
\hline LDH & $337.3(157.25,342)$ & $883(318.5,886.5)$ & $<0.001$ \\
\hline CHE & $3440.4(2232.5,4106)$ & $2956.7(1953,3713)$ & 0.007 \\
\hline Glu & $5.8 \pm 2.3$ & $6.2 \pm 2.07$ & 0.031 \\
\hline TBA & $55.9(11,64.8)$ & 82.5 & 0.0036 \\
\hline BU & $12.9(13.85,42.35)$ & $132.5(21.9,87.55)$ & $<0.001$ \\
\hline BC & $30.9(7.1,28.1)$ & $52.4(11,60.5)$ & 0.002 \\
\hline TG & $1.07 \pm 0.53$ & $1.1 \pm 0.63$ & 0.79 \\
\hline
\end{tabular}

Table 3. The analysis of factors for hepatocellular carcinoma by binary regression.

\begin{tabular}{|c|c|c|}
\hline Variable & OR $(95 \% C I)$ & $\mathbf{P}$ \\
\hline Male & $5.6(3.34-7.89)$ & 0.013 \\
\hline Age & $1.040(0.923-1.172)$ & 0.021 \\
\hline ALT & $0.986(0.937-1.037)$ & 0.042 \\
\hline AST & $1.015(0.976-1.056)$ & 0.025 \\
\hline GGT & $1.017(1.004-1.025)$ & 0.016 \\
\hline ALP & $1.004(0.996-1.013)$ & 0.026 \\
\hline LDH & $1.002(1.000-1.004)$ & 0.041 \\
\hline CHE & $0.999(0.999-1.000)$ & 0.035 \\
\hline TBA & $1.006(0.992-1.020)$ & 0.064 \\
\hline $\mathrm{BU}$ & $1.006(0.982-1.031)$ & 0.012 \\
\hline $\mathrm{BC}$ & $0.991(0.957-1.027)$ & 0.012 \\
\hline TG & $0.226(0.004-1.345)$ & 0.116 \\
\hline Tch & $0.473(0.212-0.798)$ & 0.047 \\
\hline HDL & $0.065(0.02-1.09)$ & 0.072 \\
\hline LDL & $0.04(0.01-0.09)$ & 0.045 \\
\hline APOA1 & $0.67(0.34-1.08)$ & 0.019 \\
\hline APOB2 & $0.32(0.12-0.67)$ & 0.046 \\
\hline $\mathrm{LPa}$ & $1.002(0.996-1.123)$ & 0.035 \\
\hline hs-CRP & $1.057(1.010-1.107)$ & 0.017 \\
\hline HBsAg & $2.401(1.462-3.939)$ & $<0.001$ \\
\hline DM2 & $1.82(0.871-3.833)$ & 0.011 \\
\hline Cirrhosis & $4.417(1.927-9.478)$ & 0.026 \\
\hline Portal pertension & $5.231(2.178-12.890)$ & 0.024 \\
\hline Hypertension & $1.137(0.536-2.410)$ & 0.768 \\
\hline Fatty liver & $0.27(0.19-0.76)$ & 0.024 \\
\hline
\end{tabular}

\section{Odds Ratio from Stepwise Logistic Regression Model for} HCC

We identified the effects of the independent variables associated with HCC by calculating the odds ratios through stepwise logistic regression model (Table 4). This model allowed us to identify the association among the variables based on the information of all patient cases (both control and HCC groups) enrolled. Note that it is very common that many variables exist in a high throughput data set, so multicollinearity frequently occurs when statistical models are conducted. However, multi-collinearity can lead to unstable estimates and inaccurate variances that affect hypothesis test and confidence intervals [5]. For this study, we conducted Spearman correlation analysis to detect the degree of correction between two quantitative variables, and used Contingency Coefficients to measure the degree of correlation between two category variables. In this model, HBV, gender, and DM2 were still strongly associated with HCC in the Chinese population. The values of odds ratio were trivially smaller (OR 
$=4.059, \mathrm{OR}=1.72, \mathrm{OR}=2.085$, respectively) than those in unadjusted model. The strong association between DM and HCC is consistent with cohort and case-control studies with the populations in US, Europe, and other Asian populations [6-7].

\section{Potential synergizing risk factors with DM in HCC cases}

Having established the positive correlation between DM and HCC by stepwise logistic regression analysis, we next defined the synergizing factors that may interact with DM in HCC development. For this purpose, we utilized binary logistic regression model to identify the risk factors that are positively correlated with HCC in DM cases (Table 5). Among these who were diagnosed with DM, the following risk factors are positively correlated with HCC (by comparing to the control): male gender (90.0\% vs $59.1 \%)$, age, and HBV infection (60.0\% vs $45.4 \%)$. Taken together, our results implicate the importance of frequent screening HCC in DM2 patients in the HBV prevalent area, especially for those who had HBV infection.

\section{Discussion}

Increasing evidence has suggested the association between DM and HCC in different populations [6-8]. In our study, both unadjusted logistic regression and stepwise logistic regression analysis indicated a strong and statistically significant association between DM and HCC in Chongqing population where hepatitis is endemic. Our data demonstrated that DM is strongly correlated with HCC development. DM co-coexists with HBV infection, male gender, and age in HCC development, suggesting the potential synergism among these risk factors in driving HCC. The data is consistent with the previous studies with the populations in US [9-10], Europe [7], and Asian [8,11]. Our study suggested that DM is a risk factor of HCC that may work independently or synergistically with other risk factors.

The biological mechanism for the association between DM and HCC is not well understood. Serum insulin increased in DM patients, which represents a causative factor for the association between DM and HCC. In this perspective, non-alcoholic steatohepatitis (NASH) is an onset or manifestation of DM $[12,13]$. Therefore, NASH, the most common liver disease that can be caused by metabolic dysregulation, hepatic damage, or environmental stress [14,15], may account for another mechanism underlying the association between DM and HCC. Our study clearly showed the strong association of cirrhosis with HCC (Tables 3,4). However, fatty liver is inversely correlated with HCC in the patients we investigated (Table 3 ). The negative association of hepatic steatosis with HCC may be due to the nature of this review study in which the patients with benign fatty liver diseases had been excluded from the HCC cases.

Table 4. Multivariate analyses for hepatocellular carcinoma by logistic regression.

\begin{tabular}{|c|c|c|}
\hline Variable & OR $(\mathbf{9 5} \% \mathbf{C I})$ & P \\
\hline Age & $1.034(1.010-1.058)$ & 0.005 \\
\hline ALP & $1.008(1.005-1.010)$ & $<0.001$ \\
\hline Male & $4.059(2.072-7.951)$ & $<0.001$ \\
\hline HBsAg & $1.720(1.090-2.998)$ & 0.041 \\
\hline DM2 & $2.085(0.956-4.550)$ & 0.037 \\
\hline
\end{tabular}

Table 5. The effect of DM with other risk factors on HCC.

\begin{tabular}{|c|c|c|c|c|c|c|}
\hline Variable & \multicolumn{2}{|c|}{ Control (n=22) } & \multicolumn{2}{|c|}{ HCC (n=20) } & OR(95\%Cl) & P \\
\hline & $\begin{array}{c}\text { Frequency } \\
\text { or Mean }\end{array}$ & $\begin{array}{c}\text { Pencentor } \\
\text { or SD }\end{array}$ & $\begin{array}{c}\text { Frequency } \\
\text { or Mean }\end{array}$ & $\begin{array}{c}\text { Pencentor } \\
\text { or SD }\end{array}$ & & \\
\hline Age & 57.7 & 10.7 & 62.15 & 9.2 & $1.086(1.001-1.179)$ & 0.048 \\
\hline Male & 13 & $59.1 \%$ & 18 & $90 \%$ & $10.906(1.694-73.678)$ & 0.014 \\
\hline HBsAg+ & 10 & $45.4 \%$ & 12 & $60 \%$ & $1.828(1.012-2.368)$ & 0.037 \\
\hline
\end{tabular}

We assessed the effect of each risk factor for HCC using binary logistic regression in unadjusted model (Table 3). We used stepwise logistic regression to find the most parsimonious set of predictors in predicting HCC among the independent variables (Tables 3,4). In this study, the correlation between HCC and DM was given in the context of the associations among multiple risk factors, including $\mathrm{DM}$, hypertension, gallstone, cirrhosis, fatty liver, HBV infection. Our study built adjusted stepwise logistic regression model to account for the effects of some of these variables. Table 4 shows the results of the model predicting HCC by controlling for other covariates. Our analysis results showed that the adjusted odds of HCC caused by DM are statistically significant. The adjusted odd is 2.085 by controlling for age, gender, HBsAg+, Gallstone, ChE, and ALP (Table 4). In another word, after the effects of age, gender, and HBsAg+ etc. have been considered, the patients with diabetes more likely have HCC (with the odd value of 2.085). Some limitations are present in our study. It is a retrospective, hospital-based study but not from the community. However, in this case-control study, we selected a control group that, for the known risk factors for HCC, could be considered representative population of liver disease in China. To circumvent this weakness of our study, we conducted the analysis with numerous HCC-related risk factors between the patients with benign liver diseases and HCC. This validated the accuracy of our analysis in predicting the relationship between DM and HCC.

Indeed, the positive correlation risk factors indicated by our analysis, including male gender $(\mathrm{OR}=5.60, \mathrm{p}<0.05)$, age $(\mathrm{OR}=1.040$, $\mathrm{p}<0.05)$, HBsAg $(\mathrm{OR}=2.401, \mathrm{p}<0.05)$, and cirrhosis $(\mathrm{OR}=4.417, \mathrm{p}<$ $0.05)$ (Table 3 ), were well consistent with the established conclusions [16-17]. Interestingly, HCV infection, a leading HCC risk factor, did not interact with DM in HCC development in the patient cases we reviewed. This may be due to a potential limitation of this study, which includes a relatively small number of $\mathrm{HCV}$ patients.

The findings of the current study indicate that DM patients in Chongqing are vulnerable to HCC development. Periodical screening HCC in aged male patients with DM or DM patients infected with HBV should be warranted. Such guidelines should be appropriate and safe treatment to prevent HCC development in these patients.

\section{Conflicts of interest}

All authors declare no conflict of interest.

\section{Funding}

This work was supported by National Key Clinical Specialities Construction Program of China and the National Natural Science Foundation of China (No 81501818 of Yi-shu Tang).

\section{Ethical approval}

All procedures performed in studies involving human participants were in accordance with the ethical standards of the institutional and/ or national research committee and with the 1964 Helsinki declaration and its later amendments or comparable ethical standards.

\section{References}

1. Jemal A, Bray F, Center MM, Ferlay J, Ward E, et al. (2011) Global cancer statistics CA Cancer J Clin 61: 69-90. [Crossref]

2. Parikh S, Hyman D (2007) Hepatocellular cancer: a guide for the internist. Am J Med 120: 194-202. [Crossref]

3. Hassan MM, Curley SA, Li D, Kaseb A, Davila M (2010) Association of diabetes duration and diabetes treatment with the risk of hepatocellular carcinoma. Cancer 116: 1938-1946. 
4. Tung HD, Wang JH, Tseng PL, Hung CH, Kee KM (2010) Neither diabetes mellitus nor overweight is a risk factor for hepatocellular carcinoma in a dual HBV and HCV endemic area: community crosssectional and case-control studies. Am J Gastroenterol 105: 624-631.

5. Shen J, Gao S (2008) A Solution to Separation and Multicollinearity in Multiple Logistic Regression. J Data Sci 6: 515-531. [Crossref]

6. Atchison EA, Gridley G, Carreon JD, Leitzmann MF, McGlynn KA (2011) Risk of cancer in a large cohort of U.S. veterans with diabetes. Int J Cancer 128: 635-643. [Crossref]

7. Turati F, Talamini R, Pelucchi C, Polesel J, Franceschi S, et al. (2013) Metabolic syndrome and hepatocellular carcinoma risk. Br J Cancer 108: 222-228. [Crossref]

8. Li Q, Li WW, Yang X, Fan WB, Yu JH, et al. (2012) Type 2 diabetes and hepatocellular carcinoma: a case-control study in patients with chronic hepatitis B. Int J Cancer 131: 1197-1202. [Crossref]

9. Coughlin SS, Calle EE, Teras LR, Petrelli J, Thun MJ (2004) Diabetes mellitus as a predictor of cancer mortality in a large cohort of US adults. Am J Epidemiol 159: 1160-1167.

10. [10] El-Serag HB, Tran T, Everhart JE (2004) Diabetes increases the risk of chronic liver disease and hepatocellular carcinoma. Gastroenterology 126: 460-468.
11. Ko WH, Chiu SY, Yang KC, Chen HH (2012) Diabetes, hepatitis virus infection and hepatocellular carcinoma: A case-control study in hepatitis endemic area. Hepatol Res 42: 774-781.

12. Brunt EM1 (2001) Nonalcoholic steatohepatitis: definition and pathology. Semin Liver Dis 21: 3-16. [Crossref]

13. Angulo P (2002) Nonalcoholic fatty liver disease. N Engl J Med 346: 1221-1231.

14. Zhang C, Wang G, Zheng Z, Maddipati KR, Zhang X (2012) Endoplasmic reticulumtethered transcription factor cAMP responsive element-binding protein, hepatocyte specific, regulates hepatic lipogenesis, fatty acid oxidation, and lipolysis upon metabolic stress in mice. Hepatology 55: 1070-1082.

15. Laing S, Wang G, Briazova T, Zhang C, Wang A (2010) Airborne particulate matter selectively activates endoplasmic reticulum stress response in the lung and liver tissues. Am J Physiol Cell Physiol 299: C736-C749.

16. Bosch FX, Ribes J, Díaz M, Cléries R (2004) Primary liver cancer: worldwide incidence and trends. Gastroenterology 127: S5-S16.

17. Lu SN, Su WW, Yang SS, Chang TT, Cheng KS, et al. (2006) Secular trends and geographic variations of hepatitis $\mathrm{B}$ virus and hepatitis $\mathrm{C}$ virus-associated hepatocellular carcinoma in Taiwan. Int J Cancer 119: 1946-1952.

Copyright: @2017 Tang YS. This is an open-access article distributed under the terms of the Creative Commons Attribution License, which permits unrestricted use, distribution, and reproduction in any medium, provided the original author and source are credited. 